\title{
Association Between Ambient Air Pollutants and Meteorological Factors With SARS-CoV-2 Transmission and Mortality in India: an Exploratory Study
}

\author{
Sumit Aggarwal \\ ICMR: Indian Council of Medical Research \\ Sivaraman Balaji \\ ICMR: Indian Council of Medical Research \\ Tanvi Singh \\ Indian Council of Medical Research \\ Geetha R Menon \\ Indian Council of Medical Research \\ Sandeep Mandal \\ Indian Council of Medical Research \\ Madhumathi J \\ Indian Council of Medical Research \\ Nupur Mahajan \\ Indian Council of Medical Research \\ Simran Kohli \\ Indian Council of Medical Research \\ Jasmine Kaur \\ Indian Council of Medical Research \\ Harpreet Singh \\ Indian Council of Medical Research \\ Kiran Rade \\ World Health Organisation Country Office for India \\ Samiran Panda ( $\sim$ pandasamiran@gmail.com ) \\ Indian Council of Medical Research https://orcid.org/0000-0002-5077-6275
}

Research

Keywords: COVID-19, SARS-CoV-2 transmission, Air pollutants, Meteorological, Parameters, Mortality, India

Posted Date: July 21st, 2021

DOI: https://doi.org/10.21203/rs.3.rs-728625/v1

License: (c) This work is licensed under a Creative Commons Attribution 4.0 International License. Read Full License

Version of Record: A version of this preprint was published at Environmental Health on November 19th, 2021. See the published version at https://doi.org/10.1186/s12940-021-00804-0. 


\section{Abstract}

Background: The Coronavirus disease 2019 (COVID-19) pandemic poses a serious public health concern worldwide. Certain regions of the globe were severely affected in terms of prevalence and mortality than other. Although the cause for this pattern is not clearly understood, lessons learned from previous epidemics and emerging evidences suggest the major role of ecological factors like ambient air pollutants (AAP) and meteorological parameters in increased COVID-19 incidence. The present study aimed to understand the impact of these factors on SARS-CoV-2 transmission and their associated mortality in major cities of India.

Methods: This study used secondary AAP, meteorological and COVID-19 data from official websites for the period January-November 2020, which were divided into Pre-lockdown (January-March 2020), Phase I (April to June 2020) and Phase II (July to November 2020). After comprehensive screening, five major cities that includes 48 CPCB monitoring stations collecting daily data of ambient temperature, particulate matter $\mathrm{PM}_{2.5}$ and 10 were analysed. Spearman and Kendall's rank correlation test was performed to understand the association between SARS-CoV-2 transmission and AAP and, meteorological variables. Similarly, case fatality rate (CFR) was determined to compute the correlation between AAP and COVID-19 related morality.

Results: The level of air pollutants in major cities were significantly reduced during Phase I compared to Pre-lock down and increased upon Phase II in all the cities. During the Phase II in Delhi, the strong significant positive correlation was observed between the AAP and SARS-CoV2 transmission. However, in Bengaluru, Hyderabad, Kolkata and Mumbai AAP levels were moderate and no correlation was noticed. The relation between AT and SARS-CoV-2 transmission was inconclusive as both positive and negative correlation observed. In addition, Delhi and Kolkata showed a positive association between long-term exposure to the AAP and COVID-19 CFR.

Conclusion: Our findings support the hypothesis that the particulate matter upon exceeding the satisfactory level serves as an important cofactor in increasing the risk of SARS-CoV-2 transmission and related mortality. These findings would help public health experts to understand the SARS-CoV-2 transmission against ecological variables in India and provides supporting evidence to healthcare policymakers and government agencies for formulating strategies to combat the COVID-19.

\section{Introduction}

Air pollution and meteorological factors have been shown to influence the trends of respiratory viral disease outbreaks by altering host immunity and viral survival time [1]. These factors have also been reported to be the largest environmental determinants of disease and premature death in humans, including Severe Acute Respiratory Syndrome (SARS) and Middle East Respiratory Syndrome (MERS) [2-3]. While Chronic Obstructive Pulmonary Diseases (COPD), respiratory illnesses and higher rates of hospital admission result from short-term exposure to such factors, long-term exposure to them has been associated with impaired lung function, asthma, lung cancer, heart attack, cardiovascular diseases and premature mortality [4].

The world is now facing a pandemic caused by the Severe Acute Respiratory Syndrome Coronavirus 2 (SARS-CoV-2) that started spreading from Wuhan, China, in December 2019 [5]. Most nations were forced to declare complete lockdown to contain this viral transmission. Evidence from across the globe suggests that since the major route of SARS-CoV-2 transmission is through respiratory droplets of the infected people, there is a plausible association of ambient air pollutants (AAP) such as nitrogen dioxide $\left(\mathrm{NO}_{2}\right)$, sulfur dioxide $\left(\mathrm{SO}_{2}\right)$, particulate matter (PM) 2.5 and $\mathrm{PM}_{10}$ in the viral transmission and related mortality [6-11]. Similarly, meteorological factors such as ambient temperature (AT), relative humidity (RH) etc., have been identified to promote sustained transmission of SARS-CoV-2 in China and Singapore [12-13].

In India, several studies have highlighted the link between exposure to AAP and its adverse health effects [14-15]. It is also noteworthy that the air quality index of both urban and non-urban India is significantly high [16-19]. Furthermore, India is the second most affected country by SARS-CoV-2 globally after the USA [20]. Therefore, to formulate control measures and develop policy decisions, it is important to understand the impact of AAP and meteorological factors on SARS-CoV-2 transmission, hospitalisation, severity, and mortality. Against this background, the present study was conducted to examine the association between AAP and meteorological factors that in turn could influence the SARS-CoV-2 transmission and related mortality in India.

\section{Materials And Methods}

\subsection{Data collection and screening of cities}

The study period was divided into three phases, Pre-lockdown (January-March 2020), Phase I (April-June 2020) and Phase II (July- November 2020). The rationale behind such phase separation was anticipated altered air quality across phases owing to the complete lockdown (Phase 
I) and unlocking (Phase II) enforced in India (Table 1). The present study used daily AAP and meteorological data of India, which are openly accessible from the Central Pollution Control Board's website (CPCB). In December 2020, 232 active CPCB monitoring stations located in 73 districts were assessed for the period 1 st January 2020 to 22nd November 2020. The following four criteria were kept into consideration to ensure the quality of the outcomes; i) stations with availability of at least $80 \%$ of the data for the total study duration, ii) cities with AAP level above the acceptable range as per the National Ambient Air Quality Standards (NAAQS), iii) the top ten densely populated cities and iv) cities that come under major zones (East, North, South and West) of the country, as these are the critical factor that might influence the transmission of SARS-CoV-2. Based on such considerations, Delhi, Kolkata, Mumbai, Hyderabad and Bengaluru having 48 stations, were selected for final analysis. The final list of Cities/districts and their stations selected for analyses are depicted in Fig. 1.

Table 1

Division of study duration.

\begin{tabular}{|c|c|c|c|c|}
\hline \multirow{6}{*}{$\begin{array}{l}\text { Pre-Lock } \\
\text { down } \\
(01.01 .2020- \\
31.03 .2020)\end{array}$} & \multicolumn{2}{|l|}{ Phase - 1} & \multicolumn{2}{|c|}{ Phase - 2} \\
\hline & \multicolumn{2}{|c|}{ Lockdown to Unlock 1} & \multicolumn{2}{|c|}{ Unlock 2- Unlock 6} \\
\hline & \multicolumn{2}{|c|}{ (01.04.2020-31.06.2020) } & \multicolumn{2}{|c|}{ (01.07.2020-22.11.2020) } \\
\hline & \multicolumn{2}{|c|}{ Activities permitted and prohibited } & \multicolumn{2}{|c|}{ Activities permitted and prohibited } \\
\hline & Lockdown & $\begin{array}{l}\text { Total lock down of the } \\
\text { country except the } \\
\text { movement of frontline } \\
\text { workers }\end{array}$ & $\begin{array}{l}\text { Unlock } \\
2-3\end{array}$ & $\begin{array}{l}\text { All activities including public and private transportation and } \\
\text { industries were permitted except the following outside of the } \\
\text { containment zones; Educational Research institutes, International } \\
\text { travel, Metro rail and Entertainment places }\end{array}$ \\
\hline & Unlock 1 & $\begin{array}{l}\text { Relaxation for } \\
\text { restricted interstate } \\
\text { travel, religious places, } \\
\text { hospitality services }\end{array}$ & $\begin{array}{l}\text { Unlock } \\
4-6\end{array}$ & $\begin{array}{l}\text { All kinds of activities were throughout the nation except in the } \\
\text { containment zones. } \\
\text { Restricted international travel }\end{array}$ \\
\hline
\end{tabular}

Indian Council of Medical Research (ICMR) has been collecting COVID-19 testing and diagnosis data in the centralised server, maintained by the Bioinformatics division since March 2020. This online server stores daily individual-level data regarding tests conducted, type of tests, results, socio-economic information, epidemiological and clinical profile of the tested participants etc., at the district level across all states of India. The daily data for tests conducted and positive case counts of Mumbai, Delhi, Kolkata, Hyderabad and Bengaluru were collected using Structured Query Language (SQL) for the outbreak period 1st April 2020 to 22nd November 2020. Further, the CPCB and ICMR data were analysed to understand the correlation between SARS-CoV-2 transmission, and AAP and meteorological factors.

Additionally, an association between long-term AAP exposure (Data collected from CPCB website for the period January 2015 to November 2020) and COVID-19 mortality was explored. The case fatality rate (CFR), indicating the proportion of people who died from COVID-19 among individuals diagnosed with SARS-CoV-2 infection were calculated to assess the mortality rate. The CFR data was available only for Delhi and Kolkata from the respective State official websites. Hence, they were considered for further analysis. The primary sources of data used in this study are given in Table S1.

\subsubsection{Screening of Ambient Air Pollutants (AAP) and Meteorological variables}

A comprehensive literature review was performed to identify the environmental and meteorological parameters associated with SARS-CoV-2 transmission and mortality. Six pollutants $\left(\mathrm{PM}_{2.5}, \mathrm{PM}_{10}, \mathrm{CO}, \mathrm{NO}_{2}, \mathrm{SO}_{2}\right.$, Ozone- $\left.\mathrm{O}_{3}\right)$ and four meteorological parameters (Ambient TemperatureAT, Relative Humidity - RH, Rainfall - RF, Wind Speed - WS) were initially identified. However, it was noticed that except for PM 2.5 , PM $_{10}$ and AT, variability in other parameters was minimal in the selected cities. Hence, these three parameters were considered for final analysis. The NAAQS defined by CPCB for AAP are presented in Table S2.

\subsection{Data analysis}

The extracted data were analysed for kurtosis and asymmetry. As variables were not normally distributed, non-parametric tests were conducted for analysis. The Mann Whitney Wilcoxon test, a non-parametric test for assessing the equality of means in two independent samples, was used to determine the variations in AAP levels between Pre-lock down - Phase I and Phase I - Phase II. The Kruskal-Wallis test, a non-parametric test that compares the mean rank of three are more different groups, was used to determine the variations in AAP level of the past six year's data (2015-2020). Further, Kruskal-Wallis Paired Comparisons (Conover) was carried out to know the significance among each paired group. Finally, Spearman and Kendall correlation tests were used to check for association of exposure to AAP and meteorological factors on SARS-CoV-2 transmission and mortality. 


\subsubsection{Adjusted Test Positivity Ratio (ATPR)}

Comprehending trends of test positivity ratio (TPR), which is the ratio of the number of positive test results and the number of tests performed, may lead to misinterpretation, as both the numerator and the denominator were changing due to various reasons such as scaling up of testing capacity, changes in testing criteria for COVID-19 and the number of cases at the beginning and later over the time. Therefore, an adjusted test positivity ratio (ATPR) was estimated to examine the association of AAP and AT factors with SARS-CoV-2 transmission to overcome these biases.

ATPR on the day ' $t$ ' was calculated by multiplying reported test positivity with the daily ratio of increase in cases to tests [21] using the formula, ATPR $=T P R * Z_{t}$ where $z_{t}=r_{-}$case $e_{t} / r_{\text {_test }}$ (where $r_{-}$case ${ }_{t}=C_{t}-\left(C_{t}-1\right) / C_{t}-1$ is the growth rate of cases and $r$ test $t_{t}=T_{t}-\left(T_{t}-1\right) / T_{t}-1$ is the growth rate for tests.)

In order to identify the association of AAP exposure and AT with COVID-19 ATPR, lag values of 7 and 14 days were considered. It is known that the incubation period for COVID-19 is 7.76 days, and hence a lag of 7 days has been considered [22]. Therefore, lag7 was calculated on day 't' by taking PM values for day t-7. Similarly, Lag14 was determined by taking PM values for day t-14. Because there might be a lagged association between the exposure and disease outcome thus, it is essential to take a moving-average approach to determine the lag effect of variables on SARS-CoV-2 transmission [23].

\subsubsection{Case Fatality Rate (CFR)}

In the present study, the effect of long-term exposure to AAP on COVID-19 mortality was analyzed through Case Fatality Rate (CFR). The reported CFR is the proportion of people who died from COVID-19 among individuals diagnosed over a specified period. In this ecological study model, these cities' population was assumed as constant and exposed to AAP for long-term. So, whenever a person who gets infected by COVID-19 had long-term exposure to AAP and also exposed during the course of illness till they die. Thus, to study the six-year cumulative effect of $\mathrm{PM}_{2.5}$ and $\mathrm{PM}_{10}$ on mortality due to COVID 19, the cumulative average for six years till day 't' was calculated for the period $1 \mathrm{st}$ January 2015 to 22nd November 2020.

$$
\left[T_{t}, T_{t+1} \ldots T_{n}\right]=\left[\frac{\sum_{i=1}^{t} p m 2.5_{i}}{t}, \frac{\sum_{i=1}^{t+1} p m 2.5_{i}}{t+1} \ldots \frac{\sum_{i=1}^{n} p m 2.5_{i}}{n}\right]
$$

Cumulative average $=\mathrm{T}$; Cumulative average on day $\mathrm{t}=\mathrm{Tt}$; Cumulative average on day $\mathrm{t}+1=\mathrm{Tt}+1$

Cumulative average on day $n=T n ; n=365 * 5+236=2061$. Then, to analyse the correlation between long-term exposure to AAP and COVID 19 CFR Spearman and Kendall correlation test was conducted.

\subsection{Ethics Approval}

The Institutional Ethical Committee (IEC) clearance was obtained from the Central Ethics Committee on Human Research (CECHR), Ref No. NCDIR/BEU/ICMR-CECHR/75/2020.

\section{Results}

The level of air pollutants was analysed in all the five selected cities to understand the variations in AAP levels among different study phases.

Comparison of AAP levels between Pre-lockdown and Phase I: The daily average levels of $\mathrm{PM}_{2.5}$ and $\mathrm{PM}_{10}$ were compared between Prelockdown (January-March, 2020) and Phase I (April-June, 2020) and both AAPs were found to be significantly reduced (Mann Whitney Wilcoxon Test, $\mathrm{p}<0.001$ ) during Phase I in all the cities (Table S3, Figure S1). In Kolkata, Mumbai, Bengaluru and Hyderabad, the daily average of $\mathrm{PM}_{2.5}$ significantly reduced to 351\%, 293\%, 203\%, and 123\% in Phase I compared to the Pre-lockdown Phase (Mann Whitney Wilcoxon Test, $\mathrm{p}<0.001$; Table S3, Figure S1). On the other hand, the daily average of $\mathrm{PM}_{10}$ levels decreased to $317 \%, 209 \%, 55 \%$ and $46 \%$, respectively, in Kolkata, Mumbai, Hyderabad and Bengaluru during Phase I. Interestingly, in Delhi, the 'Poor' AAP levels (as per NAAQS of India) observed in the Pre-lock down period $\left(\mathrm{PM}_{2.5} 109 \mu \mathrm{g} / \mathrm{m}^{3}\right.$ and $\left.\mathrm{PM}_{10} 250 \mu \mathrm{g} / \mathrm{m}^{3}\right)$ got drastically reduced to Satisfactory-Moderate in Phase I $\left(\mathrm{PM}_{2.5} 50.71 \mu \mathrm{g} / \mathrm{m}^{3}\right.$ and $\left.\mathrm{PM}_{10} 119.82 \mu \mathrm{g} / \mathrm{m}^{3}\right)$. However, the past five-year trend (2015-2019) was different where, the daily average of $\mathrm{PM}_{2.5}$ and $\mathrm{PM}_{10}$ levels (2015-2019) were higher by $70 \%$ and $155 \%$ when compared to the same duration in 2020 (Phase I), which was highly significant (Kruskal-Wallis test, $\mathrm{p}<0.0001$ ) (Figure S2, Table 3). 
Comparison of AAP levels between Phase I and Phase II: The comparison was made between Phase I (April-June 2020) and Phase II (JulyNovember 2020) to check for the variation in AAP levels. In all selected cities, the daily average of $\mathrm{PM}_{2.5}$ and $\mathrm{PM}_{10}$ increased again in Phase II (Figure S1). In Delhi, the daily average of PM 2.5 levels rose (84\%) from 'Satisfactory' in Phase I (50.71 $\left.\mu \mathrm{g} / \mathrm{m}^{3}\right)$ to 'Poor' in Phase II (93.81 $\mu \mathrm{g} / \mathrm{m}^{3}$ ). Also, the daily average of $\mathrm{PM}_{10}$ levels increased up to 42\% in Phase II (Table 2, Fig. 2). The 2015 to 2019 data also suggest this trend of increased AAP levels during July-November $\left(\mathrm{PM}_{2.5} 119.6 \mu \mathrm{g} / \mathrm{m}^{3}, \mathrm{PM}_{10} 257.2 \mu \mathrm{g} / \mathrm{m}^{3}\right)$ with compared to April-June $\left(\mathrm{PM} 2.585 .4 \mu \mathrm{g} / \mathrm{m}^{3}\right.$, $\left.\mathrm{PM}_{10} 217.2 \mu \mathrm{g} / \mathrm{m}^{3}\right)$ in this city. However, the AAP level increased during Phase II (2020) were lower compared to Phase I $\left(\mathrm{PM} \mathrm{M}_{2.5} 93.81 \mu \mathrm{g} / \mathrm{m}^{3}\right.$ and $\mathrm{PM}_{10} 170.55 \mu \mathrm{g} / \mathrm{m}^{3}$ ) (Table 2, Figure S1). This was about $26 \%$ and $33 \%$ of average reduction in $\mathrm{PM}_{2.5}$, and $\mathrm{PM} \mathrm{M}_{10}$ levels, respectively, compared to the past five years and were statistically significant (Kruskal-Walis test, $p<0.001$ ). Similar to Delhi, considerable increases in the AAP were observed in other cities during Phase II compared to Phase I (Figure S1, Table 2). About 184\%, 177\%, 152\% and 105\%, respectively, increase in Bengaluru, Mumbai, Hyderabad and Kolkata. The daily average of $\mathrm{PM}_{10}$ was increased up to $164 \%, 147 \%, 134 \%$ and $115 \%$ for these cities in Phase II. The Mann Whitney Wilcoxon Test shows that $\mathrm{PM}_{2.5}$ had $p$ values $<0.05$ in Mumbai and Bengaluru, which clearly shows their significant increase in these cities. Likewise, in all cities except for Kolkata, $\mathrm{PM}_{10}$ levels were significantly increased in Phase II compared to Phase I. These analyses indicated that pollution levels varied among different Phases of the study. Then, the Ambient Temperature (AT) levels were analysed in all five cities for Phase I and Phase II (Table S4). The daily average of mean AT was seen as lowest in Bengaluru $\left(24.03^{\circ} \mathrm{C}\right)$ and highest in Delhi $\left(31.53^{\circ} \mathrm{C}\right)$. Similarly, the highest and lowest daily average of maximum AT was seen in Bengaluru $\left(24.04^{\circ} \mathrm{C}\right)$ and Delhi $\left(5.08^{\circ} \mathrm{C}\right)$, respectively. 
Table 2

Descriptive statistical analysis of Particulate Matters (PM) and Ambient Temperature (AT) data.

\begin{tabular}{|c|c|c|c|c|c|c|}
\hline City & Study period & Variables & Minimum & Maximum & Mean & Standard Deviation \\
\hline \multirow[t]{9}{*}{ Bengaluru } & \multirow[t]{3}{*}{ Phase 1} & PM10 & 19 & 92 & 52.99 & 13.904 \\
\hline & & PM2.5 & 6 & 32 & 18.06 & 6.431 \\
\hline & & AT & 19 & 30 & 26.9 & 1.902 \\
\hline & \multirow[t]{3}{*}{ Phase 2} & PM10 & 19 & 143 & 60.63 & 24.308 \\
\hline & & PM2.5 & 7 & 68 & 23.11 & 11.751 \\
\hline & & AT & 21 & 27 & 24.05 & 1.24 \\
\hline & \multirow[t]{3}{*}{ Total } & PM10 & 19 & 143 & 57.76 & 21.299 \\
\hline & & PM2.5 & 6 & 68 & 21.21 & 10.363 \\
\hline & & AT & 19 & 30 & 25.12 & 2.053 \\
\hline \multirow[t]{9}{*}{ Delhi } & \multirow[t]{3}{*}{ Phase 1} & PM10 & 38 & 302 & 119.82 & 45.7 \\
\hline & & PM2.5 & 21 & 112 & 50.71 & 18.055 \\
\hline & & AT & 24 & 39 & 31.53 & 3.35 \\
\hline & \multirow[t]{3}{*}{ Phase 2} & PM10 & 29 & 723 & 170.55 & 141.277 \\
\hline & & PM2.5 & 11 & 577 & 93.81 & 99.884 \\
\hline & & AT & 20 & 36 & 29.7 & 3.687 \\
\hline & \multirow[t]{3}{*}{ Total } & PM10 & 29 & 723 & 151.2 & 117.115 \\
\hline & & PM2.5 & 11 & 577 & 77.37 & 81.973 \\
\hline & & AT & 20 & 39 & 30.4 & 3.664 \\
\hline \multirow[t]{9}{*}{ Hyderabad } & \multirow[t]{3}{*}{ Phase 1} & PM10 & 22 & 146 & 61.69 & 8.039 \\
\hline & & PM2.5 & 8 & 44 & 24.39 & 24.977 \\
\hline & & AT & 23 & 35 & 26.37 & 2.644 \\
\hline & \multirow[t]{3}{*}{ Phase 2} & PM10 & 9 & 171 & 61.22 & 21.093 \\
\hline & & PM2.5 & 5 & 80 & 28.2 & 44.275 \\
\hline & & AT & 22 & 30 & 25.66 & 1.433 \\
\hline & \multirow[t]{3}{*}{ Total } & PM10 & 9 & 171 & 61.4 & 17.391 \\
\hline & & PM2.5 & 5 & 80 & 26.75 & 38.024 \\
\hline & & AT & 22 & 35 & 25.93 & 2.009 \\
\hline \multirow[t]{9}{*}{ Kolkata } & \multirow[t]{3}{*}{ Phase 1} & PM10 & 15 & 95 & 39.57 & 14.101 \\
\hline & & PM2.5 & 7 & 60 & 19.3 & 9.801 \\
\hline & & AT & 24 & 32 & 29.02 & 1.78 \\
\hline & \multirow[t]{3}{*}{ Phase 2} & PM10 & 8 & 209 & 46.67 & 41.026 \\
\hline & & PM2.5 & 3 & 111 & 21.66 & 21.119 \\
\hline & & AT & 25 & 34 & 30.18 & 2.131 \\
\hline & \multirow[t]{3}{*}{ Total } & PM10 & 8 & 209 & 43.81 & 33.056 \\
\hline & & PM2.5 & 3 & 111 & 20.7 & 17.466 \\
\hline & & AT & 24 & 34 & 29.7 & 2.07 \\
\hline Mumbai & Phase 1 & PM10 & 17 & 108 & 47.37 & 21.296 \\
\hline
\end{tabular}




\begin{tabular}{|lllllll|}
\hline City & Study period & Variables & Minimum & Maximum & Mean & Standard Deviation \\
\hline & PM2.5 & 6 & 35 & 17.03 & 7.659 \\
\cline { 3 - 7 } & AT & 26 & 32 & 29.47 & 1.235 \\
\cline { 2 - 6 } & Phase 2 & PM10 & 11 & 221 & 71.04 & 45.965 \\
& PM2.5 & 4 & 90 & 28.76 & 22.409 \\
& AT & 25 & 30 & 27.53 & 1.216 \\
\hline \multirow{2}{*}{ Total } & PM10 & 11 & 221 & 62.01 & 40.101 \\
& PM2.5 & 4 & 90 & 24.28 & 19.096 \\
& AT & 25 & 32 & 28.27 & 1.543 \\
\hline
\end{tabular}


Table 3

Correlation coefficient analysis between COVID-19 ATPR, and daily average of mean Particulate Matters (PM) and Ambient Temperature (AT). (' + ' values are considered as positively significant and '-' values are positively significant, ${ }^{*} p<0.05,{ }^{* \star} p<0.01$ ).

\begin{tabular}{|c|c|c|c|c|c|c|c|c|c|c|c|c|}
\hline \multirow{2}{*}{$\begin{array}{l}\text { Study } \\
\text { Period }\end{array}$} & \multirow[t]{2}{*}{ Variables } & \multirow[t]{2}{*}{ Lag } & \multicolumn{2}{|c|}{ Bengaluru } & \multicolumn{2}{|l|}{ Delhi } & \multicolumn{2}{|c|}{ Hyderabad } & \multicolumn{2}{|l|}{ Kolkata } & \multicolumn{2}{|l|}{ Mumbai } \\
\hline & & & $\mathrm{K}$ & $S$ & $\mathrm{~K}$ & $S$ & $\mathrm{~K}$ & $S$ & $\mathrm{~K}$ & $S$ & K & $S$ \\
\hline \multirow[t]{9}{*}{ Phase } & \multirow[t]{3}{*}{ AT } & $\begin{array}{l}\text { No } \\
\text { lag }\end{array}$ & $-.373^{\star \star}$ & $-.531 * \star$ & $.240 \star \star$ & $.348^{\star \star}$ & $.267 \star \star$ & $.375^{\star \star}$ & -0.079 & -0.123 & $0.165^{\star}$ & $0.255^{\star}$ \\
\hline & & $\begin{array}{l}\text { Lag } \\
7\end{array}$ & $-.343^{\star \star}$ & $-.494^{\star \star}$ & $.338 * \star$ & .486 ** & 0.031 & 0.033 & -0.034 & -0.045 & -0.019 & -0.0149 \\
\hline & & $\begin{array}{l}\mathrm{Lag} \\
14\end{array}$ & $-.301 * \star$ & $-.440 * \star$ & $.263^{\star *}$ & $.385^{\star \star}$ & $0.146^{\star}$ & $0.213^{\star}$ & 0.001 & -0.008 & -0.112 & -0.1614 \\
\hline & \multirow[t]{3}{*}{ PM 2.5} & $\begin{array}{l}\text { No } \\
\text { lag }\end{array}$ & $-.308 * \star$ & $-.465^{\star \star}$ & 0.057 & 0.081 & $-.198^{\star \star}$ & $-.293^{\star \star}$ & -0.0369 & -0.032 & $-.337^{\star \star}$ & $-.476^{\star \star}$ \\
\hline & & $\begin{array}{l}\text { Lag } \\
7\end{array}$ & $-.240 \star \star$ & $-.343^{\star \star}$ & -0.055 & -0.089 & $-.356^{\star \star}$ & $-.515^{\star \star}$ & 0.01979 & 0.045 & $-.259^{\star \star}$ & $-.368 * \star$ \\
\hline & & $\begin{array}{l}\text { Lag } \\
14\end{array}$ & $-.185^{\star}$ & $-.273^{\star}$ & 0.049 & 0.086 & $-.345^{\star \star}$ & $-.509 \star \star$ & -0.0128 & -0.028 & $-.209^{\star \star}$ & $-.289 * *$ \\
\hline & \multirow[t]{3}{*}{ PM 10} & $\begin{array}{l}\text { No } \\
\text { lag }\end{array}$ & -0.0262 & -0.0582 & 0.073 & 0.104 & -0.120 & -0.1715 & 0.03128 & 0.045 & $-.237^{\star \star}$ & $-.343^{\star \star}$ \\
\hline & & $\begin{array}{l}\text { Lag } \\
7\end{array}$ & -0.0544 & -0.0777 & 0.012 & 0.014 & $-.294^{\star \star}$ & $-.448 * \star$ & 0.04731 & 0.073 & $-.178^{\star}$ & $-.259 \star$ \\
\hline & & $\begin{array}{l}\mathrm{Lag} \\
14\end{array}$ & $-.222^{\star \star}$ & $-.321 \star \star$ & 0.002 & 0.007 & $-.317^{\star \star}$ & $-.481^{\star \star}$ & -0.1329 & -0.197 & $-.249^{\star \star}$ & $-.362^{\star \star}$ \\
\hline \multirow[t]{9}{*}{$\begin{array}{l}\text { Phase } \\
\text { II }\end{array}$} & \multirow[t]{3}{*}{ AT } & $\begin{array}{l}\text { No } \\
\text { lag }\end{array}$ & 0.086 & 0.121 & $-.370^{\star \star}$ & $-.536^{\star \star}$ & $-.257^{\star \star}$ & $-.420^{\star \star}$ & 0.117 & 0.165 & $-.169^{\star \star}$ & $-.246^{\star \star}$ \\
\hline & & $\begin{array}{l}\text { Lag } \\
7\end{array}$ & 0.083 & 0.117 & $-.278^{\star \star}$ & $-.405^{\star \star}$ & $-.255^{\star \star}$ & $-.413^{\star \star}$ & 0.068 & 0.102 & $-.160^{\star \star}$ & $-.229^{\star \star}$ \\
\hline & & $\begin{array}{l}\text { Lag } \\
14\end{array}$ & 0.098 & 0.142 & $-.222^{\star \star}$ & $-.323^{\star \star}$ & $-.259^{\star \star}$ & $-.415^{\star \star}$ & 0.065 & 0.108 & -0.091 & -0.149 \\
\hline & \multirow[t]{3}{*}{ PM 2.5} & $\begin{array}{l}\text { No } \\
\text { lag }\end{array}$ & $-.370^{\star \star}$ & $-.489^{\star \star}$ & $.367^{\star \star}$ & $.528^{\star \star}$ & $-.407^{\star \star}$ & $-.591^{\star \star}$ & -0.058 & -0.091 & $-.426^{\star \star}$ & $-.607^{\star \star}$ \\
\hline & & $\begin{array}{l}\text { Lag } \\
7\end{array}$ & $-.298^{\star \star}$ & $-.399^{\star \star}$ & $.351^{\star \star}$ & $.529^{\star \star}$ & $-.492^{\star \star}$ & $-.694^{\star \star}$ & 0.005 & 0.015 & $-.392^{\star \star}$ & $-.558^{\star \star}$ \\
\hline & & $\begin{array}{l}\text { Lag } \\
14\end{array}$ & $-.236^{\star \star}$ & $-.324^{\star \star}$ & $.326^{\star \star}$ & $.492^{\star \star}$ & $-.409^{\star \star}$ & $-.605^{\star \star}$ & 0.103 & 0.148 & $-.367^{\star \star}$ & $-.533^{\star \star}$ \\
\hline & \multirow[t]{3}{*}{ PM 10} & $\begin{array}{l}\text { No } \\
\text { lag }\end{array}$ & $-.250^{\star \star}$ & $-.332^{\star \star}$ & $.372^{\star \star}$ & $.537^{\star \star}$ & $-.398^{\star \star}$ & $-.586^{\star \star}$ & -0.095 & -0.148 & $-.409^{\star *}$ & $-.577^{\star \star}$ \\
\hline & & $\begin{array}{l}\text { Lag } \\
7\end{array}$ & $-.155^{\star \star}$ & $-.208^{\star}$ & $.342^{\star \star}$ & $.522^{\star \star}$ & $-.476^{\star \star}$ & $-.682^{\star \star}$ & -0.038 & -0.049 & $-.398^{\star \star}$ & $-.561^{\star \star}$ \\
\hline & & $\begin{array}{l}\text { Lag } \\
14\end{array}$ & -0.058 & -0.075 & $.296^{\star \star}$ & $.450^{\star \star}$ & $-.378^{\star \star}$ & $-.566^{\star \star}$ & 0.073 & 0.096 & $-.378^{\star \star}$ & $-.544^{\star \star}$ \\
\hline \multirow[t]{6}{*}{$\begin{array}{l}\text { Total } \\
\text { Period }\end{array}$} & \multirow[t]{3}{*}{ AT } & $\begin{array}{l}\text { No } \\
\text { lag }\end{array}$ & $-.256^{\star \star}$ & $-.384^{\star \star}$ & -0.021 & -0.019 & -0.069 & -0.119 & 0.103 & 0.156 & $.213^{\star \star}$ & $.338^{\star \star}$ \\
\hline & & $\begin{array}{l}\text { Lag } \\
7\end{array}$ & $-.273^{\star \star}$ & $-.407^{\star \star}$ & $.088^{*}$ & $.146^{\star}$ & $-.146^{\star \star}$ & $-.227^{\star \star}$ & 0.071 & 0.107 & $.133^{\star \star}$ & $.205^{\star \star}$ \\
\hline & & $\begin{array}{l}\mathrm{Lag} \\
14\end{array}$ & $-.247^{\star \star}$ & $-.379^{\star \star}$ & $.164^{\star \star}$ & $.256^{\star \star}$ & $-.209^{\star \star}$ & $-.332^{\star \star}$ & 0.030 & 0.044 & 0.081 & 0.121 \\
\hline & \multirow[t]{3}{*}{ PM 2.5} & $\begin{array}{l}\text { No } \\
\text { lag }\end{array}$ & $-.217^{\star \star}$ & $-.305^{\star \star}$ & $.190^{\star \star}$ & $.295^{\star \star}$ & $-.279^{\star \star}$ & $-.406^{\star \star}$ & -0.031 & -0.034 & $-.376^{\star *}$ & $-.538^{\star \star}$ \\
\hline & & $\begin{array}{l}\text { Lag } \\
7\end{array}$ & $-.100^{\star}$ & $-.136^{\star}$ & $.129^{\star \star}$ & $.205^{\star \star}$ & $-.380^{\star \star}$ & $-.544^{\star \star}$ & 0.045 & 0.076 & $-.386^{\star *}$ & $-.549^{\star \star}$ \\
\hline & & $\begin{array}{l}\mathrm{Lag} \\
14\end{array}$ & -0.017 & -0.015 & $.099^{*}$ & $.169^{\star}$ & $-.352^{\star \star}$ & $-.518^{\star \star}$ & 0.092 & 0.137 & $-.384^{\star \star}$ & $-.553^{\star \star}$ \\
\hline
\end{tabular}




\begin{tabular}{|c|c|c|c|c|c|c|c|c|c|c|c|}
\hline \multirow[t]{3}{*}{ PM 10} & $\begin{array}{l}\text { No } \\
\text { lag }\end{array}$ & $-.100^{\star}$ & $-.139^{*}$ & $.218^{\star \star}$ & $.332^{* \star}$ & $-.230^{* *}$ & $-.339^{\star \star}$ & -0.024 & -0.031 & $-.343^{\star *}$ & $-.496^{* *}$ \\
\hline & $\begin{array}{l}\text { Lag } \\
7\end{array}$ & -0.053 & -0.076 & $.157^{\star \star}$ & $.251^{\star \star}$ & $-.326^{\star \star}$ & $-.476^{\star \star}$ & 0.035 & 0.055 & $-.360^{\star *}$ & $-.519^{\star \star}$ \\
\hline & $\begin{array}{l}\mathrm{Lag} \\
14\end{array}$ & -0.037 & -0.059 & $.104^{\star}$ & $.175^{* *}$ & $-.291^{* *}$ & $-.437^{\star \star}$ & 0.064 & 0.096 & $-.380^{\star *}$ & $-.548^{\star \star}$ \\
\hline
\end{tabular}

Correlation between AAP and SARS-COV-2 transmission: The effect of AAP exposure on SARS-CoV-2 transmission was analysed by performing Spearman and Kendall rank correlation for lag 0, lag 7 and lag 14 days in Phase I and Phase II (Fig. 2, Table 3). This nonparametric analysis showed a positive correlation for the daily average of mean $\mathrm{PM}_{2.5}$ and $\mathrm{PM}_{10}$ with COVID-19 ATPR $(p<0.001$ for lag 0 , lag 7, and lag 14) during Phase II and no correlation during Phase I in Delhi. The AAP level was not positively associated with the SARS-CoV-2 transmission in both Phase I and Phase II in other cities. In Bengaluru, Hyderabad and Mumbai, a negative correlation was observed for PM $\mathrm{P}_{2.5}$ and PM $_{10}$ with COVID-19 ATPR ( $<0.001$ for lag 0 , lag 7, and lag 14). Interestingly, no correlation was observed for Kolkata for the total study period. When the analysis was conducted with a daily average of maximum PM2.5 and PM10, the correlation coefficient was similar to the daily average of mean PMs (Table S5).

Correlation between AT and SARS-CoV-2 transmission: Further, the association between SARS-CoV-2 transmission and AT were analysed. The data showed both significant positive and negative correlations between AT (daily average of the maximum and mean AT) and COVID-19 ATPR among cities during both Phases (Table 3). A negative correlation between COVID-19 ATPR and AT ( $p<0.001$ for lag 0, lag 7, and lag 14) was seen in Bengaluru during Phase I and in the rest of the cities during Phase II except Kolkata. For Delhi, Hyderabad and Mumbai, a positive correlation between COVID-19 ATPR and AT ( $p<0.01$ for lag 0 , lag 7 and lag 14) were observed (Fig. 2). Notably, the correlation coefficient for both the daily average of maximum AT and mean AT were similar (Table S5).

Association between long-term exposure to AAP and COVID-19 related mortality: To investigate the effect of long-term exposure to $\mathrm{PM}_{2.5}$ and PM $_{10}$ on COVID-19 related mortality, the correlation coefficient between COVID-19 CFR and AAP were computed. In Delhi, the last six year's (January 2015 to December 2020) daily average levels of $\mathrm{PM}_{2.5}\left(102 \mu \mathrm{g} / \mathrm{m}^{3}\right)$ and $\mathrm{PM}_{10}\left(237 \mu \mathrm{g} / \mathrm{m}^{3}\right)$ found to be exceeded the permissible limit according to NAAQS in India. In Kolkata, it was $29 \mu \mathrm{g} / \mathrm{m}^{3}$ and $58 \mu \mathrm{g} / \mathrm{m}^{3}$, respectively, for $\mathrm{PM}_{2.5}$ and $\mathrm{PM}_{10}$. The Spearman and Kendall rank analysis showed that the correlation coefficients for $\mathrm{PM}_{2.5}$ were $0.64(99 \% \mathrm{Cl}, p<0.01)$ and $0.77(99 \% \mathrm{Cl}, p<0.01)$, respectively for Delhi and Kolkata, which indicates the significant positive correlation between AAP and COVID-19 CFR (Table 4). Similarly, for PM 10 , the correlation coefficients were $0.78(99 \% \mathrm{Cl}, p<0.01)$ and $0.80(99 \% \mathrm{Cl}, p<0.01)$ for Delhi and Kolkata, respectively (Fig. 3). These results show the possible association between long term exposure to AAP and COVID-19 related deaths.

Table 4

Correlation coefficient analysis between COVID19-CFR and Particulate Matters (PM). ('+' values are considered as positively significant and '-' values are positively significant, ${ }^{*} p<0.05,{ }^{*} p<0.01$ )

\begin{tabular}{|c|c|c|c|c|c|}
\hline \multirow[t]{2}{*}{ Period } & \multirow[t]{2}{*}{ Cities } & $\mathrm{PM}_{2.5}$ & $\mathrm{PM}_{10}$ & $\mathrm{PM}_{2.5}$ & $\mathrm{PM}_{10}$ \\
\hline & & \multicolumn{2}{|c|}{ Spearman_rho } & \multicolumn{2}{|c|}{ Kendall's_tau } \\
\hline \multirow[t]{2}{*}{ Phase 1} & Delhi & $-0.25^{\star \star}$ & $-0.25^{\star \star}$ & $-0.27 *$ & $-0.27 * \star$ \\
\hline & Kolkata & $0.33^{*}$ & $0.33^{*}$ & 0.51 ** & $0.51^{\star \star}$ \\
\hline \multirow[t]{2}{*}{ Phase 2} & Delhi & $0.71 * \star$ & $0.76^{*}$ & $0.60 * \star$ & $0.63^{\star \star}$ \\
\hline & Kolkata & $1.00 \star \star$ & $0.95^{\star \star}$ & $0.99 * \star$ & $0.86 * \star$ \\
\hline \multirow[t]{2}{*}{ Total study period } & Delhi & $0.64 * \star$ & $0.70 \star \star$ & $0.77 * \star$ & $0.78 \star \star$ \\
\hline & Kolkata & $0.78 * \star$ & $0.77 \star \star$ & $0.80 * \star$ & 0.78 *夫 \\
\hline
\end{tabular}

\section{Discussion}

The present study found that $\mathrm{PM}_{2.5}$ and $\mathrm{PM}_{10}$ levels were significantly reduced in all the selected cities during Phase I (Figure S1, Table S1). The past six years' data (2015-2020) of Delhi also indicated that lower $\mathrm{PM}_{2.5}$ and $\mathrm{PM}_{10}$ levels were recorded in April-June 2020 (Figure S2). The shutdown of anthropogenic activities like industries, transportation, infrastructure construction activities etc., might be the cause for this reduced emission of Particulate Matters and therefore improved air quality [24]. Similar findings were also noticed by other investigations 
conducted in Delhi, Mumbai, Chennai, Kolkata, and Bengaluru [25-28]. In addition to India, China, France, Italy, Spain, and Germany also enforced the restrictions that lead to a drastic reduction in $\mathrm{PM}_{2.5}$ and $\mathrm{PM}_{10}$ during lockdown [29-32].

Unlock phases were initiated from June 2020 in the country; however, pollutants continued to drop till August 2020 due to restricted transportation and other industrial activities (Figure S1, Figure S1, Table S1). In all five cities, the PM 2.5 level was $<40 \mu g / \mathrm{m}^{3}$ as per the NAAQS of India during July and August 2020. In the same period, the $\mathrm{PM}_{2.5}$ level fell below the NAAQS of India, i.e. $34.56 \mu \mathrm{g} / \mathrm{m}^{3}$ and 26.58 $\mu \mathrm{g} / \mathrm{m}^{3}$ for the first time in the last six years in Delhi. In contrast, $\mathrm{PM}_{2.5}$ and $\mathrm{PM}_{10}$ levels were significantly increased in the later period of Phase II as a result of increased anthropogenic activities in the country. AAP levels were reached a high level in November 2020 , where more than a $150 \%$ increase was observed in all cities, especially a $300 \%$ hike in Delhi compared to Phase I (Fig. 2). Altogether, these findings evidenced that the lockdown measures imposed in most countries to contain the spread of COVID-19 infection reduced the air pollutants that resulted in improved air quality. However, $\mathrm{PM}_{2.5}$ and $\mathrm{PM}_{10}$ levels were increased upon the ease of lockdown, as shown in our study.

In order to explore the relationship between AAP and SARS-CoV-2 transmission, the correlation between Particulate Matters level and COVID19 ATPR was analysed for Phase I and Phase II (Table 3, Fig. 2). Interestingly, we observed the phenomena when the average daily PMs were 'moderate to poor' as per the NAAQS category $\left(\mathrm{PM}_{2.5} 61-120 \mu \mathrm{g} / \mathrm{m}^{3} ; \mathrm{PM}_{10} 101-350 \mu \mathrm{g} / \mathrm{m}^{3}\right)$, there was a positive association between AAP and SARS-CoV-2 transmission. Evidently, in Delhi during Phase II, the daily average of $\mathrm{PM}_{2.5}\left(93.81 \mu \mathrm{g} / \mathrm{m}^{3}\right)$ and PM $10\left(170.55 \mu \mathrm{g} / \mathrm{m}^{3}\right) \mathrm{were}$ in the 'poor' and 'moderate' range respectively, thus, a strong positive correlation was seen (Table 3). Similarly, studies conducted across the globe noticed a strong association between AAP and COVID-19 cases, especially with the increased PMs level [29, 33-38]. However, in Mumbai, Kolkata, Hyderabad and Bengaluru, the $\mathrm{PM}_{2.5}$ and $\mathrm{PM}_{10}$ were in the 'Good' to 'Satisfactory' category $\left(\mathrm{PM}{ }_{2.5} 0-60 \mu \mathrm{g} / \mathrm{m}^{3} ; \mathrm{PM}_{10} 0\right.$ $100 \mu \mathrm{g} / \mathrm{m}^{3}$ ) so, a negative or no correlation was observed. Furthermore, the study conducted in Maharashtra (India) also observed a similar result [28]. Overall, observations from our study and others show that increased Particulate Matters beyond the moderate level found to be positively associated with SARS-CoV-2 transmission. Yet, further intensive experimental studies are required to confirm the mechanism involved in the transmission.

Further, the association between the AT (daily average of mean AT and maximum AT) and COVID-19 ATPR were analysed (Table 3, Fig. 2). The correlation analysis showed both positive and negative associations between the daily average of mean AT and COVID-19 ATPR. Delhi, Hyderabad, and Mumbai showed a positive correlation for AT in Phase I and a negative correlation in Phase II. Similar studies conducted in Mumbai and Delhi agree with our results $[28,39]$. On the other hand, Bengaluru showed a negative correlation in Phase I and no correlation in Phase II. In Kolkata, no correlation was observed in both Phases. Similar studies conducted in other countries showed positive, negative and heterogeneous associations between temperature and SARS-CoV-2 transmission [28, 40-41]. In addition, the correlation analysis between the daily average of maximum AT and COVID-19 ATPR showed similar results in both phases because of the similar pattern of variation between mean and maximum AT in all the five cities. The varying trend results observed for AT might be because of the influence of confounder or any other unknown factor that interplay with COVID-19 transmission dynamics. Overall, our results could not conclusively provide evidence on the influence of temperature on SARS-CoV-2 transmission. Future studies are needed to determine the effects of this parameter accurately.

The effect of long-term exposure to AAP on COVID-19 related morality was studied (Figure S1). When analysed for the correlation coefficient $(r)$, this long-term exposure to PMs showed a strong positive association with the COVID-19 CFR in Delhi (PM 2.5 r-0.64, PM 10 r-0.77) and Kolkata $\left(\mathrm{PM}_{2.5} \mathrm{r}-0.78, \mathrm{PM}_{10} \mathrm{r}-0.80\right)$ for the entire study duration (Fig. 3, Table 4). Studies conducted in 22 cities of India and other countries, namely Italy, the USA, China, England and France were also observed similar associations [42-47]. Moreover, researchers are investigating to elucidate the threshold level of PMs beyond which they are associated with COVID-19 mortality. A multicentric study conducted in France proposed such threshold levels of $\mathrm{PM}_{2.5}\left(15 \mu \mathrm{g} / \mathrm{m}^{3} \pm 2\right)$ and $\mathrm{PM}_{10}\left(25 \mu \mathrm{g} / \mathrm{m}^{3} \pm 4\right)$ [44]. Notably, in Delhi and $\mathrm{Kolkata}$, the $\mathrm{PM}_{2.5}$ and $\mathrm{PM}_{10}$ levels were significantly high compared to these ranges (Table 4, Fig. 3). Therefore, the present study indicates that long-term exposure to PMs is associated with COVID-19 related mortality, possibly enhancing the host susceptibility to the SARS-CoV-2 infection. However, to prove the biological plausibility of this association, strong epidemiological and experimental studies are needed [48].

Despite these interesting findings, our study has certain limitations as follows. Firstly, the data used in this study were not primarily collected for our studies. Instead, we collected data from the Indian Meteorological Department, which might have collected it for other grounds. Secondly, the daily average data used for the analysis may mask more complicated relationships with the disease, maximum ambient temperature, duration of the temperature, and exposure to high pollution. Thirdly, it is not possible to link exposure with the disease in individuals as those may not be the same in the exposed population. Hence, caution is needed when applying grouped results to the individual level. Fourthly, as COVID- 19 is contagious and primarily affected by various confounding factors including personal hygiene, host genotype, population mobility, health infrastructure, environmental determinants, and people's obedience to covid appropriate behaviour, a comprehensive investigation is essential to understand the association explicitly. Because our study could not control these factors due to the paucity of the data, with these confines, our findings should be taken as more hypothesis making rather than confirmatory.

Page 10/16 


\section{Conclusion}

The present study found that Particulate Matters' level was considerably declined during the lockdown period in all the five cities. However, they have started increasing at the later period of the Unlocking Phase. Interestingly, whenever the level of Particulate Matters exceeds the permissible range, there is a positive association between air pollutants and SARS-CoV-2 transmission, as evidenced in Delhi. On the other

hand, in cities such as Mumbai, Kolkata, Bengaluru and Hyderabad, satisfactory levels of particulate matter were observed; thus, there was no such association. In addition, the long term exposure to particulate matters showed a positive correlation with COVID-19 related mortality, which was demonstrated with the past six-year data of Delhi and Kolkata. Together, our study provides preliminary evidence that moderate to highly polluted cities are more likely to transmit SARS-CoV-2 and associated lethality than others. Thus, future studies must be conducted to determine their threshold level to minimise their transmission. However, the study findings could not provide any conclusive answer to the impact of ambient temperature on SARS-CoV-2 transmission. The current pandemic may probably end with the massive vaccine drives or with herd immunity. However, there are no such swift remedies to improve the air quality; the solitary goal must aim to mitigate the anthropogenic emission of particulate matter by switching to green energy for abating the disease burden in the future.

\section{Abbreviations}

COVID-19: Coronavirus disease 2019, SARS-CoV-2: Severe acute respiratory syndrome coronavirus 2, SARS: Severe acute respiratory syndrome, MERS: Middle East Respiratory Syndrome, COPD: Chronic obstructive pulmonary diseases, AAP: Ambient air pollutants, $\mathrm{NO}_{2}$ : Nitrogen dioxide, $\mathrm{SO}_{2}$ : Sulfur dioxide, PM: Particulate matter, $\mathrm{CPCB}$ : Central Pollution Control Board, CFR: Case fatality rate, Ozone: $\mathrm{O}_{3}$, $\mathrm{CO}$ : Carbon monoxide, AT: Ambient Temperature, RH: Relative Humidity, RF: Rainfall, WS: Wind Speed, ICMR: Indian Council of Medical Research, ATPR: WHO: World Health Organization, Adjusted Test Positivity Ratio, CECHR: Central Ethics Committee on Human Research, NAAQS: National Ambient Air Quality Standards, ACE-2: Angiotensin-converting enzyme 2.

\section{Declarations}

\section{Ethics approval and consent to participate}

The ethical approval has been obtained from the Central Ethics Committee on Human Research (CECHR) (Ref No: NCDIR/BEU/ICMRCECHR/75/2020).

\section{Consent for publication}

Not applicable

\section{Availability of data and material}

All data are publicly available, with sources described in the manuscript except for COVID-19 data as it is the restricted access datasets.

\section{Competing Interests}

The authors declare they have no competing interests.

\section{Funding}

This study was not supported by any internal or external funding agencies.

\section{Author's contribution}

SP and SA conceptualized the work. TS involved in data collection, analysis and interpretation of results. SK helped in data collection. HS and JK assisted in collecting COVID-19 datasets. KR guided in data collection and analysis. GM carried out the data analysis and statistical portion of the study. SB involved in data analysis, interpretation of results and manuscript writing. MJ and SA assisted in data collection, analysis and manuscript editing. NM helped in data collection and analysis. SM helped in data analysis. SP, SA and SB reviewed and finalized the manuscript.

\section{Acknowledgement}

Not Applicable

\section{References}


1. Mirsaeidi M, Motahari H, Taghizadeh Khamesi M, Sharifı A, Campos M, Schraufnagel DE. Climate change and respiratory infections. Ann Am Thorac Soc. 2016;13(8):1223-30.

2. Jiang XQ, Mei XD, Feng D. Air pollution and chronic airway diseases: what should people know and do? J Thorac Dis. 2016;8(1):E31.

3. Kim D, Chen Z, Zhou LF, Huang SX. Air pollutants and early origins of respiratory diseases. Chronic Dis Transl Med. 2018;4(2):75-94.

4. Rajak R, Chattopadhyay A. Short and Long Term Exposure to Ambient Air Pollution and Impact on Health in India: A Systematic Review. Int J Environ Health Res. 2020;30(6):593-617.

5. Sharma A, Tiwari S, Deb MK, Marty JL. Severe acute respiratory syndrome coronavirus-2 (SARS-CoV-2): a global pandemic and treatment strategies. Int J Antimicrob Agents. 2020;56(2):106054.

6. Coker ES, Cavalli L, Fabrizi E, Guastella G, Lippo E, Parisi ML, et al. The effects of air pollution on COVID-19 related mortality in northern Italy. Environ Resour Econ (Dordr). 2020;76(4):611-34.

7. Copat C, Cristaldi A, Fiore M, Grasso A, Zuccarello P, Santo Signorelli S, et al. The role of air pollution (PM and NO2) in COVID-19 spread and lethality: a systematic review. Environ Res. 2020;24:110129.

8. Comunian S, Dongo D, Milani C, Palestini P. Air pollution and COVID-19: the role of particulate matter in the spread and increase of COVID-19's morbidity and mortality. Int J Environ Res Public Health. 2020;17(12):4487.

9. Li H, Xu XL, Dai DW, Huang ZY, Ma Z, Guan YJ. Air pollution and temperature are associated with increased COVID-19 incidence: a time series study. Int J Infect Dis. 2020;97:278-82.

10. Setti L, Passarini F, De Gennaro G, Barbieri P, Perrone MG, Borelli M, et al. SARS-Cov-2RNA found on particulate matter of Bergamo in Northern Italy: first evidence. Environ Res. 2020;188:109754.

11. Setti L, Passarini F, De Gennaro G, Barbieri P, Pallavicini A, Ruscio M, et al. Searching for SARS-COV-2 on particulate matter: a possible early indicator of COVID-19 epidemic recurrence. Int J Environ Res Public Health. 2020;17(9):2986.

12. Lin J, Huang W, Wen M, Li D, Ma S, Hua J, et al. Containing the spread of coronavirus disease 2019 (COVID-19): Meteorological factors and control strategies. Sci Total Environ. 2020;744:140935.

13. Lin S, Wei D, Sun Y, Chen K, Yang L, Liu B, et al. Region-specific air pollutants and meteorological parameters influence COVID-19: A study from mainland China. Ecotoxicol Environ Saf. 2020;204:111035.

14. Pandey A, Brauer M, Cropper ML, Balakrishnan K, Mathur P, Dey S, et al. Health and economic impact of air pollution in the states of India: the Global Burden of Disease Study 2019. Lancet Planetary Health. 2021;5(1):e25-38.

15. Khilnani GC, Tiwari P. Air pollution in India and related adverse respiratory health effects: past, present, and future directions. Curr Opin Pulm Med. 2018;24(2):108-16.

16. Ravishankara AR, David LM, Pierce JR, Venkataraman C. Outdoor air pollution in India is not only an urban problem. Proc Natl Acad Sci USA. 2020;117(46):28640-4.

17. Sharma AK, Baliyan P, Kumar P. Air pollution and public health: the challenges for Delhi, India. Rev Environ Health. 2018;33(1):77-86.

18. Chowdhury S, Dey S, Guttikunda S, Pillarisetti A, Smith KR, Di Girolamo L. Indian annual ambient air quality standard is achievable by completely mitigating emissions from household sources. Proc Natl Acad Sci USA. 2019;116(22):10711-6.

19. Rizwan SA, Nongkynrih B, Gupta SK. Air pollution in Delhi: its magnitude and effects on health. Indian J Community Med. 2013;38(1):4.

20. World Health Organization. WHO; Geneva: 2021.WHO Coronavirus (COVID-19) Dashbord. https://covid19.who.int/. [Assessed 16 June 2021]

21. Vong S, Kakkar M. Monitoring COVID-19 where capacity for testing is limited: use of a three-step analysis based on test positivity ratio. WHO South East Asia J Public Health. 2020;9(2):141-6.

22. Qin J, You C, Lin Q, Hu T, Yu S, Zhou XH. Estimation of incubation period distribution of COVID-19 using disease onset forward time: a novel cross-sectional and forward follow-up study. Sci Adv. 2020;6(33):eabc1202.

23. Xie J, Zhu Y. Association between ambient temperature and COVID-19 infection in 122 cities from China. Sci Total Environ. 2020;724:138201.

24. Sahoo PK, Chauhan AK, Mangla S, Pathak AK, Garg VK. COVID-19 pandemic: An outlook on its impact on air quality and its association with environmental variables in major cities of Punjab and Chandigarh, India. Environ Forens. 2021;22(1-2):143-54.

25. Jain S, Sharma T. Social and travel lockdown impact considering coronavirus disease (COVID-19) on air quality in megacities of India: Present benefits, future challenges and way forward. Aerosol Air Qual Res. 2020;20(6):1222-36.

26. Bera B, Bhattacharjee S, Shit PK, Sengupta N, Saha S. Significant impacts of COVID-19 lockdown on urban air pollution in Kolkata (India) and amelioration of environmental health. Environ Dev Sustain. 2021;23(5):6913-40. 
27. Mahato S, Pal S, Ghosh KG. Effect of lockdown amid COVID-19 pandemic on air quality of the megacity Delhi, India. Sci Total Environ. 2020;730:139086.

28. Sahoo PK, Mangla S, Pathak AK, Salãmao GN, Sarkar D. Pre-to-post lockdown impact on air quality and the role of environmental factors in spreading the COVID-19 cases-a study from a worst-hit state of India. Int J Biometeorol. 2021;65(2):205-22.

29. Li L, Li Q, Huang L, Wang Q, Zhu A, Xu J et al. Azari M. Air quality changes during the COVID-19 lockdown over the Yangtze River Delta Region: An insight into the impact of human activity pattern changes on air pollution variation. Sci Total Environ. 2020;732:139282..

30. Shi X, Brasseur GP. The response in air quality to the reduction of Chinese economic activities during the COVID-19 outbreak. Geophys Res Lett. 2020;47(11):e2020GL088070.

31. Nie D, Shen F, Wang J, Ma X, Li Z, Ge P, et al. Changes of air quality and its associated health and economic burden in 31 provincial capital cities in China during COVID-19 pandemic. Atmos Res. 2021;249:105328.

32. Chen LW, Chien LC, Li Y, Lin G. Nonuniform impacts of COVID-19 lockdown on air quality over the United States. Sci Total Environ. 2020;745:141105.

33. Wang Q, Kwan MP, Zhou K, Fan J, Wang Y, Zhan D. The impacts of urbanisation on fine particulate matter (PM2. 5) concentrations: Empirical evidence from 135 countries worldwide. Environ Pollut. 2019;247:989-98.

34. Lolli S, Chen YC, Wang SH, Vivone G. Impact of meteorological conditions and air pollution on COVID-19 pandemic transmission in Italy. Sci Rep. 2020;10(1):1-5.

35. Travaglio M, Yu Y, Popovic R, Selley L, Leal NS, Martins LM. Links between air pollution and COVID-19 in England. Environ Pollut. 2021 1st January;268:115859.

36. Pansini R, Fornacca D. Higher virulence of COVID-19 in the air-polluted regions of eight severely affected countries. medRxiv. 2020; doi $: 10.1101 / 2020.04 .30 .20086496$.

37. Andrée BP. Incidence of COVID-19 and connections with air pollution exposure: evidence from the Netherlands. medRxiv. 2020; 10.1101/2020.04.27.20081562

38. Coccia M. Diffusion of COVID-19 outbreaks: the interaction between air pollution-to-human and human-to-human transmission dynamics in hinterland regions with cold weather and low average wind speed. Nat Res Council Italy 2020;729:138474.

39. Singh O, Bhardwaj P, Kumar D. Association between climatic variables and COVID-19 pandemic in National Capital Territory of Delhi, India. Environ Dev Sustain. 2021;23(6):9514-28.

40. Notari A. Temperature dependence of COVID-19 transmission. Sci Total Environ. 2021;763:144390.

41. Shahzad F, Shahzad U, Fareed Z, Iqbal N, Hashmi SH, Ahmad F. Asymmetric nexus between temperature and COVID-19 in the top ten affected provinces of China: A current application of quantile-on-quantile approach. Sci Total Environ. 2020;736:139115.

42. Fattorini D, Regoli F. Role of the chronic air pollution levels in the Covid-19 outbreak risk in Italy. Environ Pollut. 2020;264:114732.

43. Magazzino C, Mele M, Schneider N. The relationship between air pollution and COVID-19-related deaths: an application to three French cities. Appl Energy. 2020;279:115835.

44. Konstantinoudis G, Padellini T, Bennett J, Davies B, Ezzati M, Blangiardo M. Long-term exposure to air-pollution and COVID-19 mortality in England: a hierarchical spatial analysis. Environ Int. 2021;146:106316.

45. Pozzer A, Dominici F, Haines A, Witt C, Münzel T, Lelieveld J. Regional and global contributions of air pollution to risk of death from COVID-19. Cardiovas Res. 2020;116(14):2247-53.

46. Jiang Y, Wu XJ, Guan YJ. Effect of ambient air pollutants and meteorological variables on COVID-19 incidence. Infect Control Hosp Epidemiol. 2020;41(9):1011-5.

47. Mele M, Magazzino C. Pollution, economic growth, and COVID-19 deaths in India: a machine learning evidence. Environ Sci Pollut Res Int. 2021;28(3):2669-77.

48. Ali N, Islam F. The Effects of Air Pollution on COVID-19 Infection and Mortality-A Review on Recent Evidence. Front Public Health. 2020;8:580057.

\section{Figures}




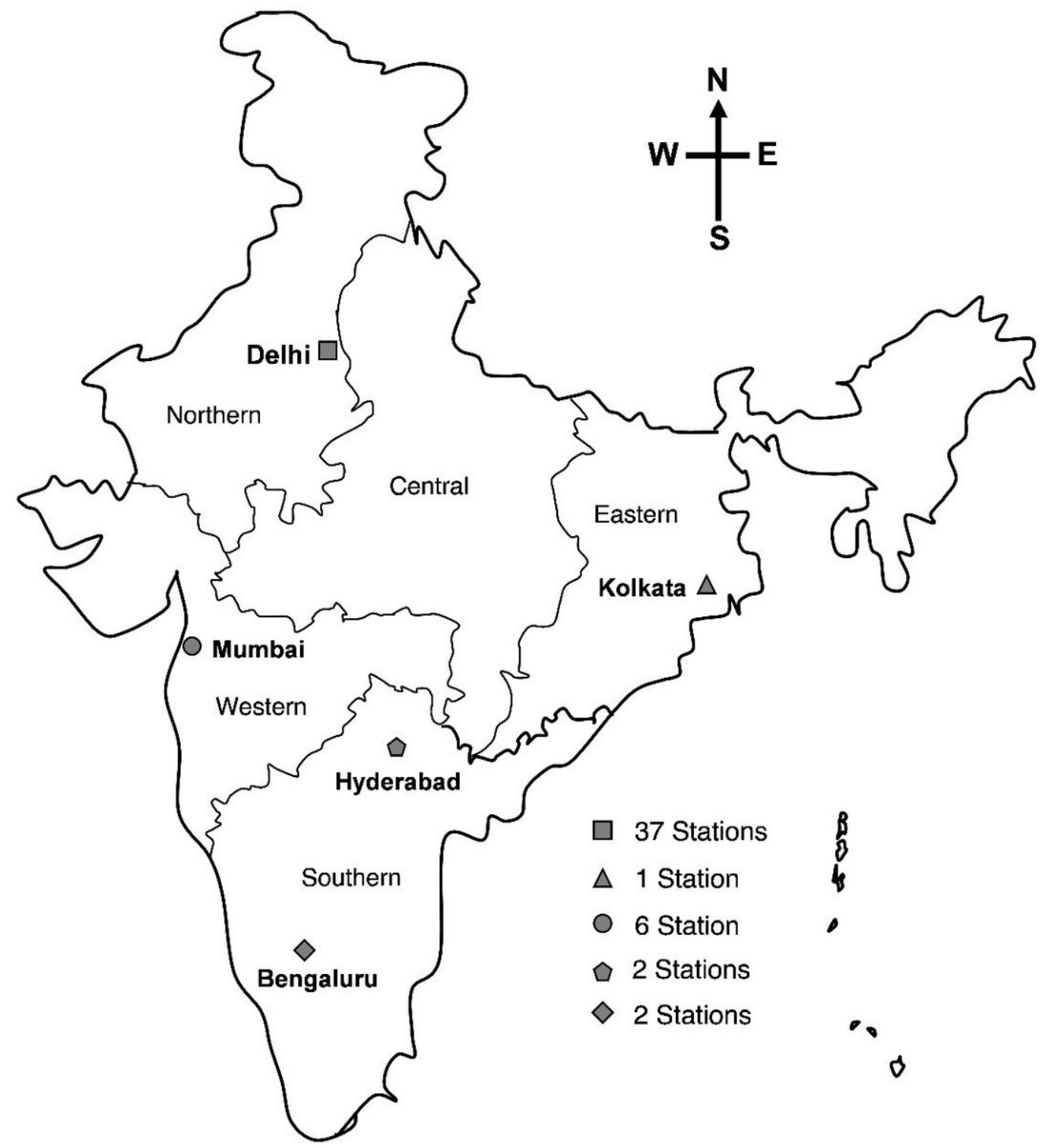

Figure 1

Cities included in the study that located in various zones of India. The number of CPCB monitoring stations used for data collection form each city are given. 


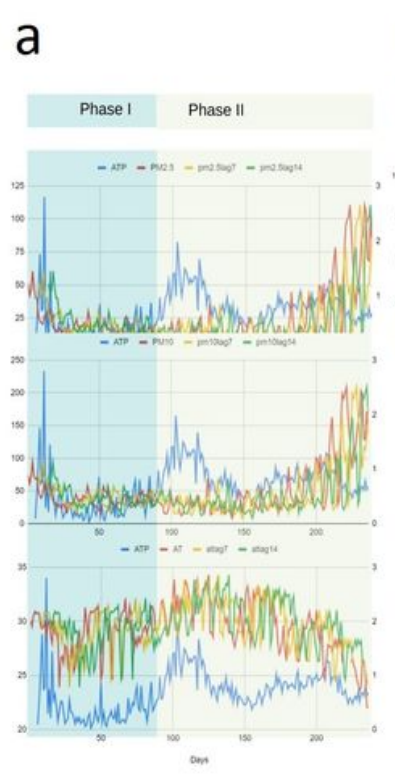

Kolkata b

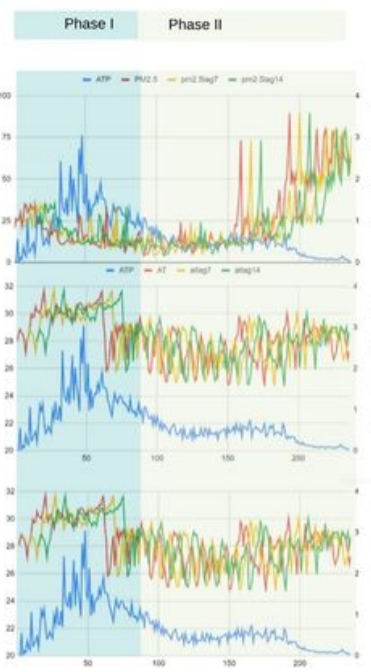

Mumbai
C
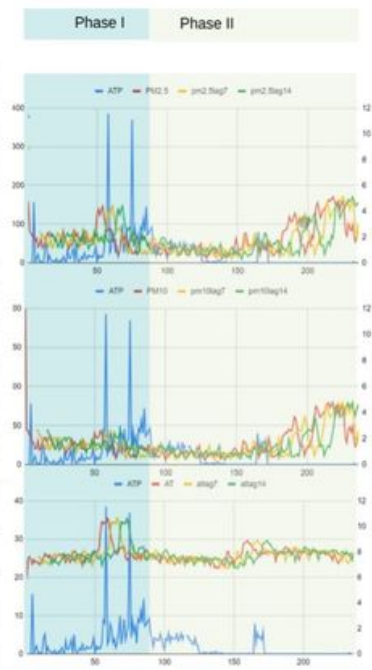

Hyderabad d

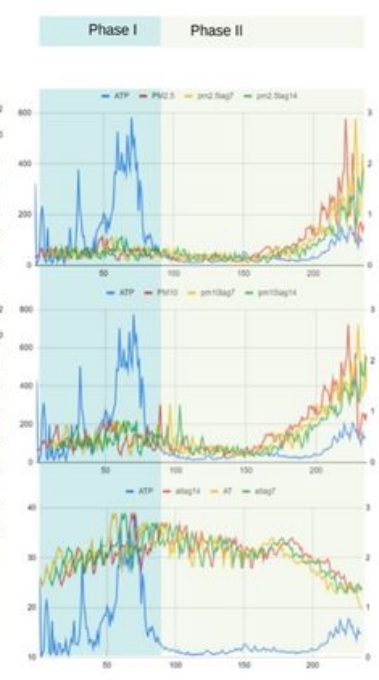

Delhi e

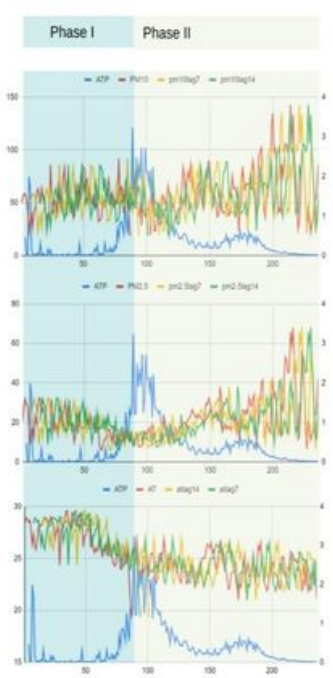

Bengaluru

\section{Figure 2}

Daily confirmed COVID-19 cases along with Ambient Air Pollutants and Ambient Temperature in Kolkata (a), Mumbai (b), Hyderabad (c), Delhi (d) and Bengaluru (e) from April 2020 to November 2020.
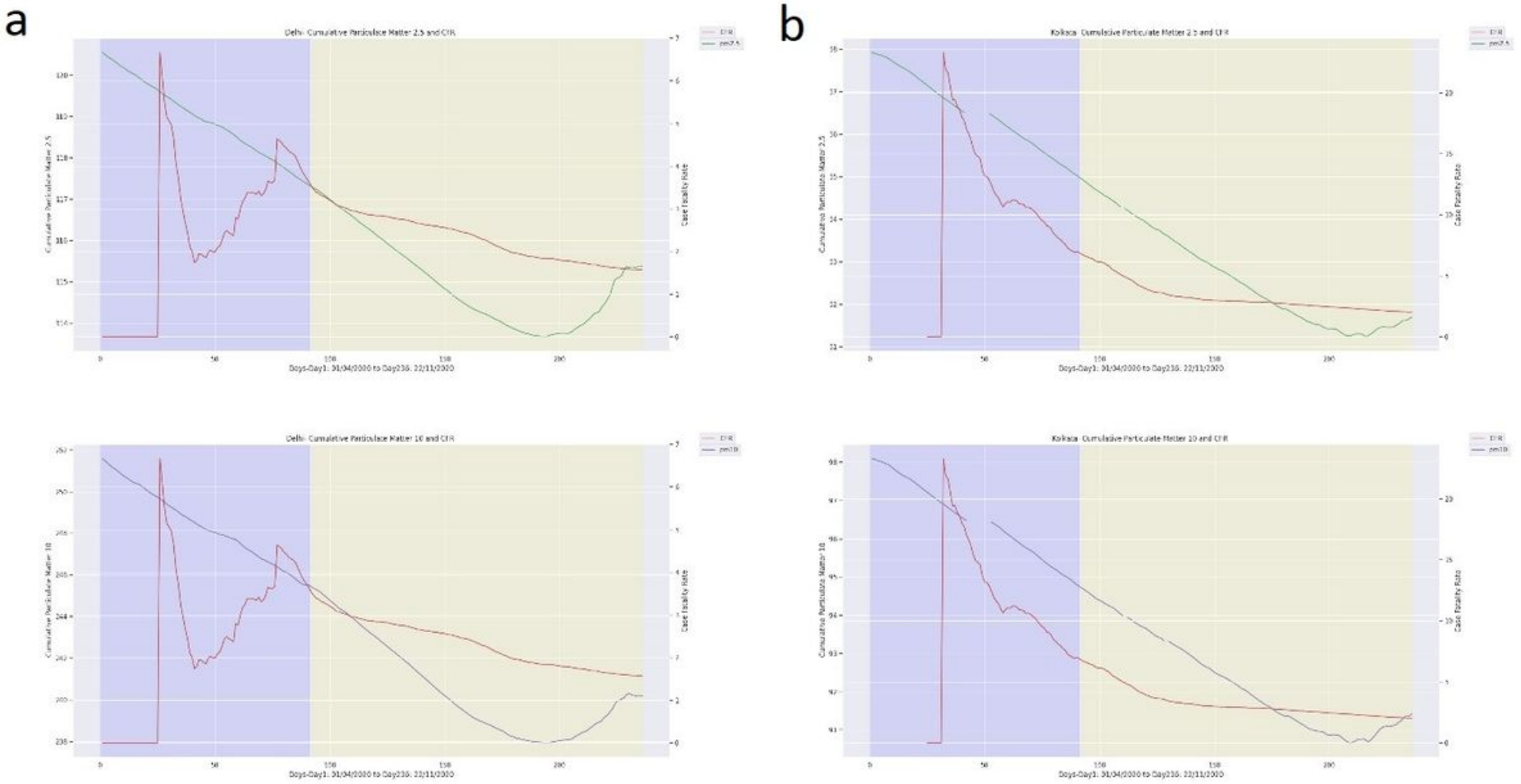

Figure 3

Daily case fatality rate (CFR) of COVID-19 and along with Ambient Air Pollutants in Delhi (a) and Kolkata (b) from April 2020 to November 2020.

\section{Supplementary Files}


This is a list of supplementary files associated with this preprint. Click to download.

- SupplmentaryMaterial.docx 